\title{
Preditores de saúde e bem-estar psicológico em adolescentes gestantes
}

\author{
Mariana Calesso Moreira ${ }^{1}$ \\ Jorge Castellá Sarriera
}

\begin{abstract}
Resumo
A pesquisa teve por objetivo avaliar os preditores de saúde e bem-estar de adolescentes gestantes. O trabalho foi desenvolvido a partir de um estudo quantitativo com uma amostra de 100 adolescentes, entre o $3 .^{\circ}$ e $9 .^{\circ}$ mês de gestação, que realizavam acompanhamento pré-natal em hospitais da rede pública de Porto Alegre. Os dados foram coletados através de um questionário para dados biodemográficos e do Questionário Geral de Saúde de Golberg, os quais foram aplicados individualmente, em sala de espera, anteriormente à consulta ginecológica. A análise dos resultados foi realizada através de uma análise descritiva, análise bivariada (ANOVA) e regressão múltipla. Estas provas indicaram que a Saúde Geral relacionou-se significativamente com algumas variáveis, tais como: idade, ocupação do companheiro e religiosidade. Além disso, o fato de não ter vivenciado um aborto e o tempo de gestação foram preditores significativos associados à Saúde Geral das gestantes. Desta forma, salienta-se para a importância de um maior número de pesquisas na área que funcionem como suporte na melhoria dos programas de intervenção e contracepção na adolescência.
\end{abstract}

Palavras-chaves: Gestação na adolescência; Saúde; Bem-estar psicológico.

\section{Health predictors and psychological well-being on pregnant adolescents}

\begin{abstract}
The purpose of this research has been to evaluate the health and well-being predictors of pregnant adolescents. The work has been developed over a quantitative study of a pattern of 100 adolescents between $3^{\text {rd }}$ and $9^{\text {th }}$ month of pregnancy, who went in for prenatal examination on publics hospitals in Porto Alegre, Brazil. Data was colleted with a questionnaire for biodemographical data and the General Health Questionnaire by Golberg, that was apply individuadly, in the waiting room, before the gynacological consult. The examination of data gained was done from descriptive analysis, Bivariate Analysis and Multiple Regression Analysis. The results showed that the health was strongly related to others variables as age, occupation of partner, and religiousness. Therefore it was possible to note that the phase of gestation and the fact of kipping pregnancy instead of having an abortion were expressive predictor related to the General Health of the pregnant. Thus it is imperative to stress the importance of more researches in this area in order to give support to the improvement of programs of intervention and contraception among teenagers.
\end{abstract}

Keywords: Pregnancy in adolescence; Health; Psychological well-being.

\section{Introdução}

A adolescência é um período do desenvolvimento humano caracterizado por mudanças físicas, psicológicas e sociais, que levam a criança à aquisição do estado adulto. As peculiaridades dessa etapa evolutiva variam e dependem do momento histórico e da sociedade em questão (Bee, 1997; Steinberg, 1985; Trad, 1999).

Nessa etapa do ciclo evolutivo, um aspecto que exige entendimento aprofundado é a sexualidade do adolescente. A tarefa de integrar seus sentimentos, valo- res morais e regras sociais em um conjunto razoavelmente coerente de crenças e condutas sexuais pessoais, constitui o esforço principal dos adolescentes em relação à sexualidade (Kimmel \& Weiner, 1998; Trad, 1999).

Porém, muitas vezes, este processo não se desenvolve de forma ideal. Assim, a gestação na adolescência pode vir como uma resposta à prática da sexualidade sem uma maturação psicológica para tanto. A gravidez precoce implica sérias mudanças no cotidiano e em aspectos emocionais desses jovens e, por essa e outras razões, trata-se de um tema que deve ser estudado em profundidade.

\footnotetext{
${ }^{1}$ Endereço para correspondência:

Av. Lavras, 400/303 - 90460-040 - Porto Alegre-RS

E-mail: mari.mor $@$,terra.com.br
} 
Algumas formas de compreender esse fenômeno são trazidas pela literatura e pesquisas na área. Um aspecto abordado é o fato de que a adolescente tem um reconhecimento de sua feminilidade através da capacidade de gerar um filho (Trad, 1999). Visto sob outro prisma, a gestação pode também estar concretizando um compromisso para toda a vida com um homem, o que implica a construção de sua própria família e, conseqüentemente, uma afirmação em relação a quem desejar, inclusive aos pais (Eiseinstein \& Souza, 1993; Kimmel \& Weiner, 1998).

Se pensarmos em relação aos jovens de classes populares, o cenário possui algumas especificidades. Adolescentes de baixa renda não encontram facilmente possibilidades de sustento, o que, muitas vezes, os torna apáticos e descrentes nas possibilidades futuras (Sanchís, 1991). É possível pensar que, sem outras formas e expectativas de vida, com carência intelectual e abandono social, a maternidade pode ser, muitas vezes, a única forma de imposição e resistência dessas jovens. Isso corresponde a uma necessidade de compensar insatisfações e tristezas, buscando preencher um sentimento inexplicável de falta de perspectivas (Luz, 1995).

Quando se comparam algumas características das adolescentes antes e depois da gravidez, percebe-se que não só os efeitos da maternidade são importantes, mas também os complexos déficits sociais e situacionais impostos pela pobreza e sexismo, experimentados por muitas dessas jovens mães (Kimmel \& Weiner, 1998).

Segundo Blanco, Rojas e De La Corte (2000), a pobreza poda a liberdade das pessoas e a sua capacidade de pensar e criticar os fatos. Além disso, a satisfação com a vida é maior em sociedades igualitárias e economicamente mais prósperas, nas quais a liberdade política e os direitos humanos são respeitados, as pessoas têm acesso à cultura e ao conhecimento, estabelecendo assim, uma relação de interdependência. A partir disso, pode-se pensar na relativa satisfação com a vida das adolescentes participantes deste estudo, os níveis de bem-estar que podem ser atingidos dentro desse contexto e quais são as perspectivas para essas futuras mães.

Dentro desse mesmo ponto de vista, a maternidade na adolescência pode ser uma forma de vitalidade, duplicidade e contornação social (Luz, 1995). No cotidiano dessas jovens predomina um sentimento de conformismo, permitindo a aceitação do dado social tal qual ele se apresenta, em sua incoerência e ambigüidade (Maldonado, 1997; Scarparo, 1996).

Diante desse contexto, cabe uma reflexão a respeito da percepção de saúde e bem-estar das adolescentes gestantes. Pode-se inferir também que esses conceitos são a base para a qualidade de vida destas jovens, o que, sem dúvida, interfere em suas relações com o meio, com o bebê e em relação à satisfação em sua vida pessoal.

Muitos autores trabalham sobre esse conceito, acrescentando aspectos relevantes para a avaliação da saúde e bem-estar psicológico do indivíduo. BuelaCasal, Carrasco Giménez e Fernández-Ríos (1997) trazem que a saúde deve ser concebida de forma positiva, através de um modelo que não se baseie na doença, mas sim na promoção de saúde, através da conexão com fatores que fazem tanto o sujeito quanto a comunidade vulneráveis às condutas saudáveis.

Para Saforcada (2001), a saúde assume uma visão mais sistêmica, ou seja, deve ser examinada em varias direções: interação da equipe de saúde com a comunidade, organização do sistema de saúde em seu conjunto, funcionamento administrativo das instituições de saúde, interações entre os grupos humanos e a relação com seu ambiente entre outros.

Outra contribuição ainda é trazida pelo modelo ecológico-contextual, o qual trabalha sobre um enfoque biopsicossocial. Nele priorizam-se as condições de saúde do ambiente e as possíveis formas de mudança estrutural e funcional que otimizam a qualidade de vida individual e social (Sarriera, 1998).

Para fins deste estudo, utilizou-se um conceito bastante abrangente de saúde, o proposto pela Organização Mundial de Saúde e pela Organização Panamericana de Saúde (1995), o qual assume pontos de convergência com as demais concepções trazidas anteriormente. A saúde é vista como um estado de bem-estar físico, psicológico e social e não como mera ausência de enfermidade (Barzelatto, 1998; Buela-Casal, Carrasco Giménez \& Fernández-Ríos, 1997; Remor, 1999). Esse conceito valoriza a saúde como recurso para a vida diária e enfatiza os aspectos sociais e pessoais, assim como as capacidades físicas (Remor, 1999).

A concepção de bem-estar psicológico também não se dá de forma padronizada dentro da literatura, uma vez que existem paradigmas teóricos diferentes, o que ocasiona uma difícil integração das posturas divergentes em um marco conceitual comum (Álvaro Estramiana, 1992; Frenández-Ríos, 1994; García Riaño, 1991; Pasquali, Gouveia, Andriola, Miranda \& Ramos, 1996).

Desta forma, o bem-estar pode ser definido como um sentimento atual, global e prazeroso, mas com projeção futura, originado pela aquisição pessoal de potencialidades e possibilidade de qualidade de vida. Nesta concepção, porém, é preciso considerar suas especificidades, como por exemplo, bem-estar subjetivo, objetivo, interno, externo, social, laboral, cultural, familiar, físico, econômico e psicológico (García Riaño, 1991), o qual está relacionado à integração entre as pes- 
soas, à aprendizagem, ao conhecimento, à mediação social, ao meio natural, à organização na comunidade e, principalmente, à saúde. Tudo isto permite ao indivíduo um maior nível de satisfação em sua vida diária (Argyle, 1993).

Stevenson, Maton e Teti (1999) constataram, através de uma pesquisa realizada com gestantes adolescentes, que o bem-estar não difere em adolescentes que têm como companheiro o pai de seus filhos ou que namoram outra pessoa sem ser o pai do bebê. Entretanto, gestantes adolescentes que mantêm uma relação conjugal com o pai de seus filhos possuem maior autoestima, domínio da situação e baixos nívis de depressão, diferentemente das que não possuem uma moderada qualidade no relacionamento com estes.

Já Vázquez Márquez, Almirall Chávez, Cruz Chávez e Álvarez Amoeda (1997) têm uma visão menos otimista. As autoras acreditam que a gravidez na adolescência é um indicativo negativo de saúde, o qual pode acarretar sérias conseqüências para o bebê principalmente, até o primeiro ano de vida. Tal ponto de vista é também compartilhado por Crouch (2002) em um artigo sobre a saúde reprodutiva das adolescentes, no qual a autora menciona as conseqüências negativas da gestação para a saúde e para e bem-estar da jovem e para sua família de um modo geral.

Assim, ao abordar o fenômeno da gravidez na adolescência, devemos sempre levar em conta as redes sociais de apoio, a qualidade de vida dessas jovens e os meios que a sociedade lhes oferece para conseguir uma melhoria das condições de saúde. Desta forma, se ampliará a discussão e as possíveis intervenções sobre o tema, saindo do âmbito individual para atingir também o âmbito social.

O presente artigo tem como objetivo avaliar a Saúde Geral e dimensões específicas (Stress Psíquico, Desejo de Morte, Desconfiança no Próprio Desempenho, Distúrbios do Sono e Distúrbios Psicossomáticos) das adolescentes gestantes, identificando seus preditores entre as variáveis biodemográficas.

\section{Procedimentos metodológicos}

\section{Participantes}

A pesquisa contou com a participação de 100 adolescentes gestantes, entre 12 e 19 anos, residentes da cidade de Porto Alegre ou região metropolitana, que realizavam acompanhamento pré-natal em hospitais da rede pública de Porto Alegre. Todas as participantes estavam no mínimo no terceiro mês de gestação. A escolha das participantes foi realizada pelo critério de conveniência e de acordo com a disponibilidade do local e das gestantes no momento da coleta dos dados.

É importante salientar que todas as adolescentes responderam aos questionários mediante a apresentação do consentimento informado. Tal consentimento foi elaborado de acordo com o Comitê de Ética dos hospitais que participaram do estudo.

$O$ perfil das adolescentes pesquisadas apresentou as seguintes características: $56 \%$ da amostra encontrava-se entre os 16 e 17 anos $(M=16,25)$ e $54 \%$ tinham o ensino fundamental completo. Sobre a ocupação das participantes, $41 \%$ apenas estudavam, $3 \%$ estudavam e trabalhavam fora, $6 \%$ somente trabalhavam fora e não estavam estudando no momento da coleta de dados, $22 \%$ tinham como ocupação as tarefas domésticas, não possuindo outra atividade profissional nem estudantil na ocasião e $28 \%$ mencionaram não ter nenhum tipo de ocupação, uma vez que não estudavam, não trabalhavam e não eram responsáveis pelas tarefas domésticas.

O tempo de gestação das adolescentes apresentou-se de forma homogênea, demonstrando três intervalos bem definidos. Do $3 .^{\circ}$ ao $4 .^{\circ}$ mês de gestação encontravam-se $24 \%$ das participantes, do $5 .^{\circ}$ ao $6 .^{\circ}$ mês, encontravam-se $43 \%$ e do $7 .^{\circ}$ mês em diante, $33 \%$ das gestantes. O tempo médio de gestação foi de 5 meses $(M=5,68 ; d p=1,61)$ e a ocorrência de outras gestações bastante baixa, atingindo somente $8 \%$ das adolescentes.

A grande maioria das participantes $(92 \%)$ não havia passado por nenhuma experiência de aborto, porém, dentre as que já o haviam vivenciado, nenhuma relatou mais que um episódio. O grupo também manteve-se homogêneo em relação a manutenção e uma relação estável, uma vez que $90 \%$ das adolescentes tinham um companheiro fixo e apenas $10 \%$ não mantinham nenhuma relação estável no momento. Cabe ressaltar que todas as adolescentes que tinham um companheiro no momento da pesquisa, este era o pai do bebê que elas esperavam.

A ocupação do companheiro variava bastante, sendo que a maioria trabalhava fora $(70 \%)$, alguns apenas estudam $(10 \%)$, outros estavam desempregados (4\%) e $12 \%$ não têm nenhuma ocupação, ou seja, não trabalhavam nem estudavam no momento da coleta de dados, não demonstrando também interesse em empregar-se no momento.

Parte das adolescentes moravam com seus companheiros $(33 \%)$, com seus pais e irmãos $(27 \%)$ ou somente com sua mãe e irmãos (20\%). A renda das participantes também se mostrou bastante variada, sendo que mais da metade da amostra (63\%) concentrou-se no intervalo de 200,00 a 600,00 reais mensais. No que diz respeito à religiosidade, $90 \%$ participantes relataram 
Tabela 1 - Resultados de Saúde Geral e seus fatores média e desvio padrão

\begin{tabular}{lcc}
\hline & Média & Desvio Padrão \\
\hline Saúde Geral & 1,91 & 0,44 \\
Desejo de Morte & 1,41 & 0,63 \\
Stress Psíquico & 0,96 & 0,25 \\
Desconfiança no Próprio Desempenho & 1,93 & 0,42 \\
Distúrbios do Sono & 1,93 & 0,72 \\
Distúrbios Psicossomáticos & 2,00 & 0,51 \\
\hline
\end{tabular}

ter uma religião, sendo que a prevalecente foi a católica $(76 \%)$. No entanto, somente $64 \%$ consideravam-se praticantes.

\section{Instrumentos}

Primeiramente, foi realizada uma entrevista para a obtenção de dados biodemográficos (idade, grau de escolaridade, ocupação atual, relações conjugais, ocupação do companheiro, com quem mora, renda familiar e religião) e informações a respeito da gestação (tempo de gestação, gestações anteriores e abortos prévios). Tal entrevista serviu também como rapport para a posterior aplicação dos instrumentos.

A aplicação dos instrumentos foi realizada de forma individual no momento em que as adolescentes acudiam a uma das consultas do pré-natal. Os hospitais ofereceram um espaço físico de seus ambulatórios para que os autores do estudo pudessem realizar as entrevistas anteriormente à consulta com o ginecologista.

\section{Questionário de Saúde Geral de Goldberg - QSG}

O QSG é composto de 60 itens e os participantes respondem em uma escala tipo Likert (1 a 4), a qual permite que se possa estabelecer o grau de severidade do sintoma apresentado. Sendo assim, a interpretação dos escores ocorre de forma que, quanto maior for o escore, maior será o nível do distúrbio observado.

No estudo de adaptação e validação à realidade brasileira (Pasquali, Gouveia, Andriola, Miranda \& Ramos, 1996), os autores encontraram uma excelente consistência interna do QSG como fator único $(\alpha=0,95)$, assim como instrumento de medida de seus fatores separadamente. Desta forma, o QSG pode ser utilizado como uma variável única que mede a Saúde Geral dos respondentes ou ainda a partir de cinco dimensões específicas de saúde, significativamente correlacionadas, sendo elas: Stress Psíquico, Desejo de Morte, Desconfiança no Próprio Desempenho, Distúrbios do Sono, Distúrbios Psicossomáticos.

\section{Resultados}

\section{Análise descritiva: Saúde Geral e dimensões especificas}

As médias obtidas a partir do instrumento utilizado (Saúde Geral, $\mathrm{M}=1,91$; Desejo de Morte $\mathrm{M}=1,41$; Stress Psíquico, M=0,96; Desconfiança no Próprio Desemprenho e Distúrbios do Sono, $\mathrm{M}=1,93$; Distúrbios Psicossomáticos, $\mathrm{M}=2,00)$ indicaram que as participantes apresentavam um bom nível de saúde e bem-estar durante a gestação, o que levou a pensar que não se sentiam estressadas nem deprimidas nesse momento de suas vidas.

Análise bivariada: Saúde Geral e seus fatores associada às variáveis biodemográficas

Foram realizadas também algumas análises bivariadas (ANOVA - teste Tukey), com o objetivo de analisar o quanto Saúde Geral das participantes e seus fatores poderiam estar relacionados ou não com as variáveis independentes pesquisadas.

Assim, Saúde Geral demonstrou estar significativamente relacionada $(p=0,042)$ à ocupação do companheiro. Os resultados apontam para a ocorrência de dois grupos bem definidos: as adolescentes cujo companheiro exercia alguma função (trabalho ou estudo) ou adolescentes cujo companheiro estava desempregado.

Tabela 2 - Resultados significativos da ANOVA entre Saúde Geral e seus fatores com as variáveis biodemográficas

\begin{tabular}{lcc}
\hline & $\mathrm{F}$ & Sig \\
\hline Saúde Geral o Ocupação do companheiro & 2,84 & 0,042 \\
Distúrbios do Sono e Idade da gestante & 2,68 & 0,051 \\
Stress Psíquico e Religião & 3,33 & 0,040 \\
Desconfiança no Próprio Desempenho e Religião & 3,17 & 0,046 \\
\hline
\end{tabular}


Tabela 3 - Variáveis preditoras de Saúde Geral - modelo final de regressão

\begin{tabular}{cccccc}
\hline \multicolumn{2}{c}{ Unstardardized Coefficients } & \multicolumn{4}{c}{ Standardized Coefficients } \\
\hline $\begin{array}{c}\text { Variáveis do modelo } \\
\text { (constant })\end{array}$ & $\mathrm{B}$ & Std. Error & Beta & $\mathrm{T}$ & $\mathrm{Sig}$ \\
\hline Abortos & 0,591 & 0,253 & 0,228 & 2,336 & 0,029 \\
Tempo de gestação & $5,598 \mathrm{E}-02$ & 0,27 & 0,220 & 2,052 & 0,022 \\
$\mathrm{R}=0,297$ & $\mathrm{R}^{2}=0,088$ & $\mathrm{R}^{2}$ ajustado $=0,069$ & & \\
\hline
\end{tabular}

Cabe ressaltar que as gestantes pertencentes ao primeiro grupo demonstraram ter um melhor nível de saúde e bem-estar perante aquelas que pertenciam ao segundo grupo.

Em relação aos Distúrbios do Sono, percebe-se que estes estão relacionados com a idade das participantes $(p=0,051)$. Assim, pode-se salientar, novamente, a ocorrência de dois grupos: adolescentes gestantes entre 12 e 15 anos demonstraram menores níveis de Distúrbios do Sono do que adolescentes entre 16 e 19 anos, o que leva a pensar que os Distúrbios do Sono estão mais relacionados ao período final da adolescência.

A religiosidade das participantes mostrou-se relacionada a alguns fatores referentes a sua saúde Geral, tais como Stress Psíquico $(\phi=0,040)$ e Desconfiança no Próprio Desempenho $(p=0,046)$. Cabe salientar que ambas as relações possuem a mesma direção, ou seja, as gestantes que possuíam alguma crença ou prática religiosa alcançavam níveis mais altos nesses dois fatores.

Análise de regressão múltipla: Preditores de saúde entre as adolescentes gestantes

A análise de regressão múltipla (método stepwise) tinha o objetivo de determinar quais eram as variáveis que poderiam ser consideradas como preditoras de saúde e bem-estar entre as adolescentes gestantes pesquisadas.

Assim, apenas duas variáveis mostraram ser preditoras de saúde entre as participantes: número de abortos realizados e tempo de gestação. Tal procedimento forneceu um coeficiente de variância explicada
$\left(\mathrm{R}^{2}\right)$ de 0,088 , o que determina que essas variáveis preditoras explicam somente $8,8 \%$ da Saúde Geral das participantes.

Em relação à ocorrência de abortos, foi obtido um coeficiente $\beta=0,228$ e $p=0,029$, o que denota que o fato de ter praticado um aborto pode ser considerado uma variável preditora de mal-estar entre as gestantes pesquisadas, uma vez que as adolescentes que já realizaram algum aborto apresentam um deterioro no seu estado de saúde e bem-estar maior do que as que não o realizaram.

A variável tempo de gestação pôde também ser considerada como preditora de saúde e bem-estar entre as participantes $(\beta=0,220$ e $p=0,022)$, no sentido de que quanto maior o tempo de gestação, pior é o estado de saúde das participantes.

No que se refere à Desconfiança no Próprio Desempenho, notou-se que as variáveis preditoras são as mesmas que em relação a Saúde Geral, porém com um coeficiente de variância explicada $\left(\mathrm{R}^{2}\right)$ de 0,108 .

A variável referente à ocorrência de abortos apresentou um coeficiente $\beta=0,258$ e $p=0,009$, demonstrando ser preditora da Desconfiança no Próprio Desempenho. Percebeuse então, que adolescentes que já realizaram algum aborto apresentaram maior Desconfiança no Próprio Desempenho do que as que não o realizaram. Já a variável tempo de gestação teve um coeficiente $\beta=0,215$ e $p=0,028$ o que indicou que adolescentes com uma gestação em estágio mais avançado demonstraram ter maior Desconfiança no Próprio Desempenho.

Tabela 4 - Variáveis preditoras de Desconfiança no Próprio Desempenbo - modelo final de regressão

\begin{tabular}{cccccc}
\hline \multicolumn{2}{c}{ Unstardardized Coefficients } & \multicolumn{4}{c}{ Standardized Coefficients } \\
\hline $\begin{array}{c}\text { Variáveis do modelo } \\
\text { (constant })\end{array}$ & $\mathrm{B}$ & Std. Error & Beta & $\mathrm{T}$ & Sig \\
\hline Abortos & 0,630 & 0,235 & 0,258 & 2,679 & 0,009 \\
Tempo gest. & $5,639 \mathrm{E}-02$ & 0,025 & 0,215 & 2,225 & 0,028 \\
$\mathrm{R}=0,329$ & $\mathrm{R}^{2}=0,108$ & $\mathrm{R}^{2}$ ajustado $=0,090$ & & & \\
\hline
\end{tabular}


Tabela 5- Variável preditora do Desejo de Morte - modelo final de regressão

\begin{tabular}{cccccc}
\hline \multicolumn{2}{c}{ Unstardardized Coefficients } & \multicolumn{4}{c}{ Standardized Coefficients } \\
\hline $\begin{array}{c}\text { Variáveis do modelo } \\
\text { (constant) }\end{array}$ & $\mathrm{B}$ & Std. Error & Beta & $\mathrm{T}$ & Sig \\
\hline Abortos & 0,901 & 0,360 & 0,245 & 2,505 & 0,014 \\
$\mathrm{R}=0,245$ & $\mathrm{R}^{2}=0,060$ & $\mathrm{R}^{2}$ ajustado $=$ & 0,051 & & \\
\hline
\end{tabular}

Analisando o fator referente ao Desejo de Morte foi possível perceber que este trouxe como variável

preditora somente a ocorrência de abortos. Tal fato é observado através de um coeficiente de variância explicada $\left(\mathrm{R}^{2}\right)$ de 0,060 demonstrando que essa variável explica $6 \%$ do Desejo de Morte entre as participantes.

A variável apresentou um coeficiente $\beta=0,245$ e $p=0,01$, demonstrando ser preditora em algum nível do Desejo de Morte entre as adolescentes pesquisadas. Assim, as adolescentes que já haviam realizado algum aborto apresentaram maior Desejo de Morte do que as que não o haviam realizado.

Pode-se concluir, então, que os baixos níveis de variância explicada em relação à Saúde Geral da gestante expressam que, possivelmente, outros fatores, que não somente as variáveis biodemográficas estudadas tenham maior poder explicativo do que as variáveis selecionadas.

\section{Discussão}

Os resultados obtidos neste estudo suscitam algumas reflexões sobre a amostra estudada. A Saúde Geral das participantes mostrou-se relacionada com a ocupação de seus companheiros, ou seja, gestantes cujo companheiro não tinha nenhuma ocupação apresentaram um estado de Saúde Geral debilitado do que aquelas com companheiros inseridos profissionalmente.

Assim, pode-se pensar que o fato de assumir uma relação estável com um homem que, na maioria das vezes $(70 \%)$, tem trabalho e renda fixa, proporciona maior tranqüilidade para a gestante. Isto porque pressupõe-se que esse companheiro também seja o responsável por boa parte do suprimento das condições básicas de sua nova família.

Alfonso Fraga e Álvarez Suárez (1998) relatam uma pesquisa realizada em vários hospitais ginecoobstétricos em Cuba. Nesse estudo, a maioria dos adolescentes que acompanhavam suas companheiras trabalhava fora, sendo que das adolescentes que interromperam a gravidez, somente $20 \%$ foram acompanhadas de seus companheiros. Entre as que tiveram o filho, a porcentagem foi maior.

Assim, é possível verificar a importância que o suprimento afetivo, social e econômico representa para uma adolescente que engravida. A partir disso, pode-se levantar um questionamento sobre a valorização do papel do homem e sua responsabilidade sobre a gravidez consumada.

Por outro lado, os Distúrbios do Sono apareceram relacionados à idade das participantes. Adolescentes com idade mais avançada apresentaram mais Distúrbios do Sono do que as mais novas, o que aponta para um deterioro no estado de saúde e percepção de bem-estar dessas jovens.

Esta diminuição da saúde das adolescentes mais velhas talvez se justifique pelo seu possível maior amadurecimento, o qual permite uma visão clara das dificuldades que serão enfrentadas a partir da gestação e que se concretizam com o nascimento do filho. Outra hipótese é que o projeto de vida e as metas estabelecidas por uma adolescente mais velha talvez estejam mais estruturados e, deste modo, a gestação implique em um adiamento ou até mesmo, uma suspensão de aspirações anteriormente desejadas.

Os projetos vitais dos adolescentes assumem maior ou menor consistência conforme seu nível de autoconhecimento e das habilidades em saber lidar com o meio social. Entretanto, verificam-se dificuldades próprias da faixa etária e de uma experiência escolar prejudicada, o que sugere a necessidade de reforçar a auto-estima e estimular o melhor conhecimento de suas potencialidades (Sarriera, Pizzinato, Ríspoli, Trindade \& Lópes, 2000).

Obteve-se também uma relação significativa no que diz respeito a algumas dimensões do conceito de Saúde Geral (Stress Psíquico e Desconfiança no Próprio Desempenho) e o fato de as adolescentes possuírem alguma prática religiosa. A crença em alguma religião mostrouse associada a maiores níveis entre estas duas dimensões, o que sinaliza um deterioro de sua saúde e sentimento de bem-estar.

As práticas sexuais fora do casamento são condenadas pela Igreja Católica e boa parte das religiões de raiz judaico-cristãs, assim como a utilização dos métodos anticoncepcionais (Barsted, 1998). A partir disso, pode-se pensar em alguns pressupostos religiosos e nos sentimentos que estes podem gerar em uma adolescente que engravida. $\mathrm{Na}$ amostra estudada, composta principalmente por adolescentes da religião católica, pode-se 
levantar um questionamento sobre o sentimento de culpa eventualmente originado a partir dessa prática sexual "desviante", a qual se concretiza com a gravidez. Esses sentimentos podem haver contribuído para que as adolescentes demonstrassem estar mais desconfiadas em relação a sua capacidade e desempenho nas funções maternas.

Kotchick, Shaffer, Forehand e Miller (2001), em um estudo que trabalha os comportamentos sexuais de risco na adolescência, trazem algumas pesquisas que relacionam a religiosidade ao adiamento da iniciação sexual. Nessas pesquisas, a religião não é tida como preditora dos comportamentos sexuais de risco, mas está relacionada ao uso de preservativos nas relações sexuais.

No caso dessas jovens, não se deve excluir a possibilidade de que, muitas delas, tenham pensado em interromper a gestação, mesmo que posteriormente isto não tenha se concretizado. Sendo assim, pode-se dizer que as que possuem alguma prática religiosa não se tenham sentido totalmente livres para realizar essa escolha e talvez estivessem vivenciando uma gestação possivelmente não desejada.

Laganá (1999) aborda a importância da religiosidade na determinação do uso de métodos contraceptivos. A autora menciona que adolescentes católicas aceitam menos a liberdade de escolha da mulher em relação à reprodução do que as que não são católicas.

Assim, questiona-se neste momento a "utilização" feita pelas jovens pesquisadas em relação a sua crença religiosa. É possível levantar a hipótese de que essas adolescentes não demonstram sentir-se apoiadas por sua crença, mas sim de alguma forma pressionadas por ela.

O presente estudo encontrou como variáveis preditoras de Saúde Geral o tempo de gestação $(\beta=$ $0,220$ e $p=0,022)$ e o fato das adolescentes já terem vivenciado ou não um aborto ( $\beta=0,228$ e $p=0,029)$. Assim, nota-se que a ocorrência de um aborto anterior à atual gestação, gera um decréscimo no estado de saúde e bem-estar, bem como quanto mais avançado for o tempo de gestação, pior parece ser o estado de saúde das participantes.

Em relação a outros fatores relacionados à percepção de saúde, a amostra comportou-se da mesma forma, porém em alguns não foram encontrados preditores de saúde e bem-estar entre as variáveis biodemográficas. No que diz respeito ao fator relativo a Desconfiança no Próprio Desempenho, obtiveram-se os mesmos preditores que em Saúde Geral e em relação ao fator relativo a Desejo e Morte, somente a variável referente aos abortos vivenciados demonstrou ter importância.
Sendo assim, algumas questões podem ser levantadas se refletirmos sobre o tempo de gestação dessas jovens que realizavam pré-natal nos serviços durante a coleta dos dados. O atendimento pré-natal, desde o início da gestação, ajuda a prevenir a prematuridade e outras complicações que podem acompanhar esse processo. Quando a gravidez não é planejada, a adolescente tende a negar essa possibilidade, o que, consequentemente, retarda o diagnóstico e promove o início tardio ou sem a freqüência adequada, dos cuidados com o bebê. Esse atendimento pode atuar também como modelo de cuidados que a jovem prestará a seu filho (Eisenstein \& Souza, 1993; Szigethy \& Ruíz, 2001)

A partir disso, é possível inferir algumas razões pelas quais o avanço da gestação contribui negativamente para a saúde e bem-estar dessas jovens. Uma das possíveis causas para esse fenômeno é o fato de que, com a aproximação do parto, alguns temores em relação a saúde física e a do bebê se tornem presentes. Muitas mudanças ocasionam-se nesse momento e, para a grande maioria das adolescentes pesquisadas, essa era uma situação que ainda não havia sido enfrentada, uma vez que $92 \%$ delas eram primíparas.

Szejer e Stewart (1997) mencionam que no terceiro trimestre da gravidez são freqüentes as preocupações referentes ao nascimento e à preparação para o parto. Ocorre uma percepção mais concreta da gestação, bem como da função materna, além de representar um momento delicado, que suscita ansiedades referentes ao exercício da maternidade e ao recebimento do bebê. Vale lembrar que o fato de a gestação estar chegando ao final também esteve relacionado à Desconfiança no Próprio Desempenho, sendo esse um dos fatores que compõem o conceito de Saúde Geral.

Os sentimentos em relação à maternidade talvez se concretizem com a aproximação do nascimento do filho e com isso, se faça presente a ambivalência em relação à troca de papéis. Algumas limitações sociais também são pertinentes a essa etapa, como o abandono da escola ou do emprego, de forma que esse tende a ser um período de grande expectativa, mas também apreensão por parte da adolescente gestante.

As dificuldades que a conjuntura macro e microssocial impõe para muitas adolescentes faz com que estas não cheguem ao final de gestação e tendam a interrompê-la, mesmo que esse processo ainda não seja legalizado e possa trazer sérias conseqüências para sua saúde. Em relação às adolescentes pesquisadas, obtevese uma pequena freqüência de gestantes que já haviam realizado algum aborto, apenas $3 \%$, ainda que essa variável fosse considerada um proditor de saúde.

Tal questão talvez se justifique pelo fato de as jovens terem desejado consciente ou inconscientemen- 
te, engravidar, dado o qual não foi explorado durante a entrevista, ou também pelas perspectivas de vida que possuem. Muitas dessas adolescentes não demonstraram ter tido seus projetos de vida significativamente alterados pela gestação, uma vez que já viviam com seus companheiros ou já haviam deixado a escola, por exemplo.

Tal dado parece ter relação com os resultados obtidos em outras pesquisas (Barsted, 1998; Kalil \& Kunz, 1999; Ourô \& Leal, 1998) que encontraram uma tendência maior ao aborto por jovens de um maior poder aquisitivo, já que a gestação pode ter diferentes significados e implicações, dependendo do contexto social no qual o fenômeno é observado.

Sendo assim, talvez se possa pensar que esses fatores influenciem a baixa incidência na amostra da interrupção provocada da gravidez, juntamente com as dificuldades reais que essas jovens teriam para realizar um aborto. O aborto não é uma prática legalizada e, desta forma, não pode ser feito nos hospitais públicos, ou seja, precisariam ser realizados em clínicas particulares ou feitos de forma nada segura, segundo alguns métodos caseiros.

Os sentimentos decorrentes de um aborto são marcas e experiências emocionais bastante intensas e difíceis de serem esquecidas e metabolizadas por uma jovem ainda com seu psiquismo em formação. É possível que com a chegada de uma nova gestação, esses sentimentos voltem à tona, ocasionando maior ansiedade e preocupação durante a nova gestação, o que poderia influenciar, de alguma forma, a percepção de saúde e bem-estar destas jovens.

\section{Conclusões}

Desta forma, pode-se afirmar que, em relação à amostra estudada, as adolescentes demonstraram apresentar um bom nível de saúde durante a gestação. No entanto, alguns fatores parecem ocasionar um deterioramento nesse estado, sendo eles o fato de já haver vivenciado um aborto e aproximação do final da gestação. Além disso, outras variáveis de cunho biodemográfico também influenciam tal processo, sendo elas a idade das participantes e o fato de possuir ou não alguma crença religiosa e ter um companheiro em situação sociolaboral estável. Ainda que a predição do nível de saúde geral por parte desses fatores deva ser relativizada ao grupo específico, os mesmos podem servir de indicadores para o estudo da saúde reprodutiva e da sexualidade na adolescência.

\section{Referências}

Alfonso Fraga, J. C. \& Álvarez Suarez, M. (1998). Rol masculino y disminución de la fecundidad: el caso cubano. Em E. D. Bilac \& M. I. B. Rocha (Eds.). Saúde reprodutiva na América e no Caribe - Temas e Problemas. (pp. 211-236). Campinas: Editora 34.

Álvaro Estramiana, J. L. (1992). Desempleo y bienestar psicológico. Madrid: Siglo XXI de España.

Argyle, M (1993). Psicología y la calidad de vida. Intervención psicosocial, 6(2), 5-15.

Barsted, L. A. L. (1998). Sexualidade e reprodução: estado e sociedade. Em E. D. Bilac \& M. I. B. Rocha (Eds.). Saúde reprodutiva na América Latina e no Caribetemas e problemas (pp. 147-181). Campinas: Editora 34.

Barzelatto, J. (1998). Desde el control de natalidad hacia la salud sexual y reprodutiva: la evolución de un concepto a nivel internacional. Em E. D. Bilac \& M. I. B. Rocha (Eds.). Saúde reprodutiva na América Latina e no Caribe - temas e problemas (pp. 39-50). Campinas: Editora 34.

Bee, H. (1997). O ciclo vital. Porto Alegre: Artes Médicas.

Blanco, A., Rojas, D. \& De La Corte, L. (2000). La psicología e su compromiso con el bienestar humano. Em A Blanco, D. Rojas, L. De la Corte, J. D. Delius, J. J. M. Tobla, R. Frenández-Ballesteros, M. T. A. Argilaga \& M. J. Díaz-Aguado (Eds.). Psicología y Sociedad (pp. 9-46). Valencia: Real Sociedad Económica de Amigos del País.

Buela-Casal, G., Carrasco-Giménez, T. J. \& FernandezRíos, L. (1997). Psicología preventiva - avances recientes en técnicas y programas de prevención. Madrid: Pirámide.

Crouch, V. (2002). Teenage pregnancy and sexual health. Community Practitioner, 75(3), 82-87.

Eisenstein, E. \& Souza, R. P. (1993). Situacõoes de risco à saúde de crianças e adolescentes. Petrópolis: Vozes.

Fernández-Ríos, L. (1994). Manual de Psicología Preventiva. Madrid: Siglo XXI de España.

Garcia Riaño, D. (1991). Calidad de vida: aproximacíon histórico-conceitual. Boletín de Psicología, 30, 55-94.

Kalil, A. \& Kunz, J. (1999). First births among unmarried adolescent girls: Risck and protective factors. Social Work Research, 23(3), 197-208.

Kimmel, J. \& Weiner, R. (1998). La adolescencia: una transición del desarrollo. Barcelona: Ariel Psicología.

Kotchick, B., Shaffer, A., Forehand, R. \& Miller, K. S. (2001). Adolescent sexual risk behavior: A multi- 
system perspective. Clinical Psychology Review, 21(4), 493-519.

Laganá, L. (1999). Psychosocial correlates of contraceptive practices during late adolescence. Adolescence, 34(135), 463-482.

Luz, A. M. H. (1995). A vida cotidiana da mulher adolescente: sexualidade, gravidez e maternidade no Rio Grande do Sul, 1920-1995. (Tese de doutorado não publicada), Porto Alegre: PUCRS.

Maldonado M. T. (1997). A psicologia da gravideæ: São Paulo: Saraiva.

Organização Mundial de Saúde/ Organização Panamericana de Saúde. (1995). Evaluación 1990-1994 - plan de acción regional para la reducción de la mortalidad materna en las América. Washington, D. C.

Ourô, A. M. \& Leal, I. P. (1998). O ventre sacia-se, os olhos não: o suporte social em adolescentes que prosseguiram a gravidez e mulheres que recorrem à interrupção voluntária da gravidez na adolescência. Análise Psicológica, 3(16), 441-446.

Pasquali, L., Gouveia, V. V., Andriola, W. B., Miranda, F. J. \& Ramos, A. L. M. (1996). Questionário de saúde geral de Goldberg. São Paulo: Casa do Psicólogo.

Remor, E. A. (1999). Psicologia da saúde: apresentação, origens e perspectivas. Psico, 30(1), 205-217.

Saforcada E. (2001). El factor bumano en la salud pública. Buenos Aires: Proa XXI.

Sanchís, E. (1991). De la escuela al paro. Madrid: Siglo Veintiuno.

Sarriera, J. C. (1998). O modelo ecológico-contextual em psicologia comunitária. Em L. Souza, M. Freitas \& M. Rodrigues (Eds.). Psicologia: reflexões (im)pertinentes (pp. 373-3960). São Paulo: Casa do Psicólogo.
Sarriera, J. C., Pizzinato, A., Rispoli, A., Trindade, T. V. C. \& Lópes, V. B. (2000). Adolescentes de classes populares à procura de trabalho: suas dificuldades e expectativas. Psicologia Argumento, 26, 85-104.

Scarparo, H. (1996). Cidadãs brasileiras: o cotidiano de mulheres trabalhadoras. Rio de Janeiro: Revan.

Steinberg, L. (1985). Adolescence. New York: Alfred Knopf Inc.

Stevenson, W., Maton, K. I. \& Teti, D. M. (1999). Social support, relationship quality, and well-being among pregnant adolescents. Journal of Adolescence, 22(1), 109-121.

Szejer, M. \& Stewart, R. (1997). Nove meses na vida da mulher. São Paulo: Caso do Psicólogo.

Szigethy, E. M. \& Ruíz, P. (2001). Depression among pregnant adolescents: an integrated treatment approach. American Journal of Psycbiatry, 158(1), 22-27.

Trad, P. (1999). Assessing the patterns that prevent teenage pregnancy. Adolescence, 34(133), 221-240.

Vázquez Márquez, A.; Almirall Chávez, A. M.; Cruz Chávez, F. \& Álvarez Amoeda, E. (1997). Embarazo en la adolescencia: repercusión biosocial durante el primer año de vida. Revista Cubana de Pediatria, 69(2), $82-88$.

Sobre os autores:

Mariana Calesso Moreira é psicóloga, mestre em Psicologia Clínica pela Pontifícia Universidade Católica do Rio Grande do Sul ( PUCRS) y doutoranda em Psicopatología Clínica i de la Salut pela Universitat Autónoma de Barcelona (UAB).

Jorge Castellá Sarriera é psicólogo, doutor em Psicologia Social pela Universidad Autónoma de Madrid (UAM), professor dos programas de graduação e pós-graduação da Faculdade de Psicologia da PUCRS e coordenador do Grupo de Pesquisa em Psicologia Comunitária na mesma Universidade. Pesquisador do CNPq. 